\title{
LEAVING RESIDUAL VARUS ALIGNMENT AFTER TOTAL KNEE ARTHROPLASTY DOES NOT IMPROVE PATIENT OUTCOMES
}

\author{
R. Michael Meneghini MD ${ }^{1,2}$ \\ Tanner W. Grant BS ${ }^{1}$ \\ Marshall K. Ishmael BS ${ }^{2}$ \\ Mary Ziemba-Davis BA ${ }^{2}$
}

\footnotetext{
${ }^{1}$ Indiana University School of Medicine, Department of Orthopaedic Surgery, $1120 \mathrm{~W}$.

Michigan Street, Room 600, Indianapolis, IN 46202

${ }^{2}$ Indiana University Health Physicians Orthopedics and Sports Medicine, IU Health Saxony Hospital, 13100 East $136^{\text {th }}$ Street, Suite 2000, Fishers, IN 46037
}

Corresponding Author:

R. Michael Meneghini, MD

Indiana University Health Physicians Orthopedics and Sports Medicine

Indiana University School of Medicine, Department of Orthopaedic Surgery

$13100136^{\text {th }}$ Street

Suite 2000

Fishers, IN 46037

Phone: 317-688-5980

Email: rmeneghi@iuhealth.org

This is the author's manuscript of the article published in final edited form as:

Meneghini, R. M., Grant, T. W., Ishmael, M. K., \& Ziemba-Davis, M. (2017). Leaving Residual Varus Alignment after Total Knee Arthroplasty Does Not Improve Patient Outcomes. The Journal of Arthroplasty. http://dx.doi.org/10.1016/j.arth.2017.02.064 


\title{
LEAVING RESIDUAL VARUS ALIGNMENT AFTER TOTAL KNEE ARTHROPLASTY DOES NOT IMPROVE PATIENT OUTCOMES
}

\begin{abstract}
Introduction: Recent popularity of kinematic alignment and constitutional varus has caused some surgeons to leave varus limbs in moderate residual varus after total knee arthroplasty (TKA). The purpose of this study was to determine if patients with native varus alignment preoperatively who are left in residual varus after TKA would have improved outcomes compared to those fully corrected to neutral alignment.
\end{abstract}

Methods: A retrospective review of 361 consecutive primary TKA's was performed. Anatomic tibiofemoral alignment was measured preoperatively and postoperatively on digital radiographs, and knees were categorized as neutral, varus, or valgus based on accepted criteria. Modern Knee Society Scores, three individual Knee Society questions (pain with level walking, pain with stairs or inclines, does this knee feel normal), and UCLA Activity Level scores were collected at minimum one-year follow-up.

Results: After exclusions for confounds $(n=73)$ and loss to follow-up $(n=26), 262$ consecutive knees were available for analysis, $67 \%$ (176) of which were preoperatively varus. Sixty-six percent of varus knees were corrected to neutral, $25.6 \%$ were left in residual varus, and $8.5 \%$ were corrected to valgus. Median Knee Society objective scores at latest follow-up were greater in knees corrected to neutral (97), followed by knees corrected to varus (95), and valgus (93) ( $p$ $=0.025)$, but post hoc comparisons between pairs of medians were not significant. There was no difference between groups in any other outcome measure $(p \geq 0.245)$, the amount of improvement from baseline ( $p \geq 0.423$ ), or with respect to the amount of varus correction 
measured in $3^{\circ}$ increments $(p \geq 0.118$ ). Sixty percent of native varus patients corrected to neutral, $64 \%$ of those corrected to varus, and $40 \%$ of those corrected to valgus reported that their knee felt normal $(p=0.193)$.

Conclusion: Findings fail to support the notion that leaving varus knees in residual varus and avoiding full correction to neutral alignment during TKA will improve outcomes and pain. Until longer-term follow up is obtained, caution is advised when leaving limbs in residual varus after TKA.

Keywords: total knee arthroplasty; total knee replacement; residual varus; alignment 


\section{Introduction}

Tibiofemoral alignment after total knee arthroplasty (TKA) historically has been mechanically restored to neutral alignment of $180^{\circ} \pm 3^{\circ}$ resulting in good clinical and functional outcomes [1,2] and increased implant longevity. [3-8] Traditional tenets support that malalignment outside of mechanically neutral alignment may lead to increased shear stress on polyethylene components, particularly when left in varus, leading to excessive wear as well as premature aseptic loosening $[7,9,10]$. More recently, however, implant survivorship at 15 years has been shown to be equivalent in neutral, varus, and valgus aligned knees [11-13], calling into question the long-held tenet that neutral mechanical alignment is a requisite for long-term TKA success and survivorship. Further, computer navigation, designed to more accurately achieve neutral mechanical alignment through a reduction in outliers, has not been shown to robustly improve clinical and functional outcomes following TKA. [14-16]

How limb alignment affects patient satisfaction and patient reported outcomes remains controversial. Patient reported satisfaction following TKA remains a disappointing 70-89\% [1723]. While the underlying cause(s) of dissatisfaction with TKA is unknown, it was recently observed that only $66 \%$ of patients reported that their knee felt normal following TKA, and 33 to 54\% reported residual symptoms and functional problems. [24] Interestingly, the authors reported a trend for more patients with kinematically aligned knees reporting that their knee felt normal compared to patients with mechanically aligned knees.[24] Consequently, some have recently challenged the notion of neutral mechanical alignment being the standard of care during TKA because it may be inconsistent with native knee anatomy and gait. [25] Bellemans and coauthors reported that "constitutional varus," described as at least $3^{\circ}$ natural varus limb alignment, occurs in $17 \%$ of asymptomatic women and $32 \%$ of asymptomatic men.[25] Further, the 
concept of kinematic alignment, the premise of which is restoring the knee alignment to the prediseased state after TKA, has gained interest with some reports of improved [26] or neutral [27] outcomes compared to conventional neutral mechanical alignment. The purpose of the current study was to evaluate the effect of the change in direction and amount of preoperative to postoperative coronal alignment after TKA on modern patient reported outcomes and specifically whether leaving preoperative varus limb alignment in residual varus improved patient outcomes compared correcting to neutral alignment after TKA.

\section{Methods}

This IRB-approved, retrospective cohort analysis included 361 consecutive primary TKAs performed between September 2010 and October 2014 with cruciate retaining femoral implants. Seventy-three exclusions included cases with posteriorly stabilized implants (21), orthopedically complex cases such as those requiring hardware removal (12), constrained polyethylene liners (11), early revision (9), medical complications following surgery (6), early infection or wound complications (5), un-resurfaced patellas (4), previous surgeries on the index knee (1), and death prior to minimum one-year follow-up (4). Among the remaining 288 cases, $26(9 \%)$ were lost to minimum one-year follow-up, leaving a final sample of 262 cases available for analysis.

A single surgeon performed all study TKAs using the same anesthesia and perioperative pain management protocol. Procedures were performed using a median parapatellar approach. A consistent rehabilitation regimen was completed by each patient to minimize any risk of confounding variables related to rehabilitation and functional outcomes. The Triathlon® Total Knee Replacement System (Stryker Orthopaedics, Mahwah, NJ) was used in all TKAs. Twohundred and twenty implants (84\%) were cemented and 42 were cementless or hybrid fixation 
(cemented tibia/cementless femur). For 69 procedures conventional intramedullary femoral alignment guides were used to cut the femur and extra-medullary alignment guides were used to cut the tibia. An abbreviated computer navigation technique was used for the remaining 193 TKAs. Navigation consisted of an articulating surface-mounted computer-assisted surgery system to enact the distal femoral cut, and conventional alignment techniques to enact the remaining cuts (including femoral implant rotation, tibial slope, and coronal alignment). Regardless of the alignment methodology used for the femur, the alignment target and goal was perpendicular to the mechanical axis. The tibial component target goal was essentially neutral mechanical axis, utilizing extra-medullary alignment guides to place the implant perpendicular to the anatomic axis of the tibia. Further, in general, if were going to err in component position, we would allow error in varus for those knees in substantial varus alignment but we did not intentionally leave knees in varus or target so-called kinematic alignment. Patient age, sex, race, and body mass index (BMI) were recorded at the time of surgery.

Patients received preoperative and postoperative short knee radiographs at their follow-up clinic visits per standard of care. Radiography was performed by a trained and certified orthopedic radiologist using standard and accepted techniques. Preoperative and postoperative weight-bearing anteroposterior (AP) view radiographs were accessed and measured in the Synapse ${ }^{\circledR}$ software system (Fujifilm, USA). If multiple images were available, the image with the best quality was used. Preoperative and postoperative tibiofemoral angle was assessed by measuring and bisecting two sets of points based on femoral and tibial landmarks. Calibration was unnecessary due to distances being unrelated to the angle being measured.

The distal-most aspect of the femoral condyle was located and tracked $60 \mathrm{~mm}$ proximally to the cortical edge of the femur. The same technique was performed on the medial and lateral 
sides to create the first set of femoral points. The second set of femoral points was created by measuring $30 \mathrm{~mm}$ proximally from the first set of points along the cortical edges $(90 \mathrm{~mm}$ from the distal-most condyle). These two sets of femoral points were then bisected to create the femoral line (Figure 1).

The tibial line was created in similar methodology to the femoral line (Figure 1). The proximal-most aspect of the tibia was identified. A $60 \mathrm{~mm}$ measurement distally was performed to the cortical edge of the tibia. The first set of points was marked on the cortical edges for both the medial and lateral sides. The second set of points was measured $30 \mathrm{~mm}$ distally from the first set of points ( $90 \mathrm{~mm}$ from the proximal-most portion of the tibia). Bisecting these two sets of points created the tibial line. Extending the femoral line distally and tibial line proximally into the joint space to create an intersection point allowed the angle measurement tools in Synapse ${ }^{\circledR}$ to measure the angle between the femoral line and the tibial line. The same measurements were taken to establish postoperative tibiofemoral angles.

Knees were categorized preoperatively and postoperatively based on tibiofemoral angle. Knees with alignment between $+3^{\circ}$ and $+8^{\circ}$ were categorized as neutrally aligned, knees with alignment $\leq+2^{\circ}$ were categorized as varus, and knees with alignment $\geq 9^{\circ}$ were categorized as valgus. The pre- to postoperative direction of change in tibiofemoral angle was identified for each patient (i.e., neutral to neutral, varus to neutral, etc.). Preoperative tibiofemoral angle was subtracted from postoperative tibiofemoral angle to identify the amount of change in alignment angle in degrees.

Patient-reported outcomes were evaluated during standard-of-care clinic visits preoperatively and a minimum of one-year postoperatively. The new Knee Society objective (KSSO; 100 total possible points), satisfaction (KSSS; 40 total possible points), and function 
(KSSF; 100 total possible points) scores [28, 29] and the University of California Los Angeles (UCLA) Activity Level score [30, 31] were measured at each clinic visit. Ranging from a low of 1 point (wholly inactive) to a high of 10 points (regularly participate in impact sports), the UCLA Activity Level score asks patients to choose their highest level of current activity. Three individual questions from the new Knee Society Score questionnaire were analyzed as standalone items: pain with level walking $(0=$ worst, $10=$ severe $)$, pain with stairs or inclines $(0=$ worst, $10=$ severe), and "does this knee feel normal to you (always, sometimes, never).

\section{Statistical Analysis}

Minitab 17 (State College, PA) was used to analyze latest, minimum one-year outcomes and pre- to postoperative changes (delta) in patient reported outcomes based on the direction and amount of change in $3^{\circ}$ increments $\left(0^{\circ}\right.$ to $2^{\circ}, 3^{\circ}$ to $5^{\circ}$, etc. $)$ in tibiofemoral angle following TKA. The relationship between age, sex, race, BMI, and conventional vs. abbreviated computer navigation for bone cuts also were evaluated in relation to the direction of change in alignment angle. Anderson-Darling tests using alpha $\leq 0.05$ revealed that with the exception of delta KSSS and delta KSSF, none of the continuous independent or dependent variables were normally distributed. Consequently, for most outcomes, the Kruskal-Wallis $(\mathrm{H})$ test of medians adjusted for ties was used in place of one-way ANOVA (F) for group comparisons.

\section{Results}

Sixty-seven percent (176/262) of sample knees were preoperatively varus. Mean and median tibiofemoral angle in preoperatively varus knees were $-3.6^{\circ}\left(\operatorname{SD} 4.0^{\circ}\right.$ ) and $-3.0^{\circ}$, respectively. Sixty-six percent $(n=116 / 176)$ of the native varus sample was female, with an average age and BMI of 65.0 (SD 9.0; range 34 to 88) years and 34.6 (SD 7.1; range 19.3 to 
$14857.9) \mathrm{kg} / \mathrm{m}^{2}$, respectively. Eighty-nine percent of native varus patients were Caucasian and $11 \%$ 149 were Black. Average length of follow-up was 25.2 (SD 11.0; 8.7 to 64.9) months. separately based on the direction of alignment change following TKA. Sixty-six percent (65.9\%; 116/176) were corrected to neutral alignment, $25.6 \%$ (45/176) were left in residual varus, and $8.5 \%(15 / 176)$ were overcorrected to valgus alignment. Postoperative alignment (neutral, valgus, varus) of native varus knees did not vary based on patient sex $\left(\mathrm{X}^{2}=1.941, p=0.379\right)$, race $\left(X^{2}=1.532, p=0.465\right)$, or the use of computer navigation $\left(X^{2}=0.627, p=0.731\right)$. Patients corrected from varus to valgus were significantly younger than patients corrected from varus to neutral (median age 61.1 years vs. 65.8 years, $p=0.0095$ ), with no differences in median age observed for patients corrected from varus to varus (65.9 years). There was a significant difference in median BMI in patients corrected from varus to varus $\left(36.0 \mathrm{~kg} / \mathrm{m}^{2}\right)$ compared to those corrected from varus to neutral $\left(33.2 \mathrm{~kg} / \mathrm{m}^{2}, p=0.014\right)$, with no differences observed for patients corrected from varus to valgus $\left(31.3 \mathrm{~kg} / \mathrm{m}^{2}\right)$. It also is important to note that, with one exception, outcome scores in the preoperatively varus sample did not differ based on cemented compared to cementless/hybrid fixation type $(p \geq 0.127)$. Median UCLA Activity Level Score at latest follow-up was one-point higher in patients with cementless/hybrid fixation knees (6 vs. 5, $\mathrm{W}=11464.0, p=0.025)$, corresponding to the difference between regularly and sometimes participating in moderate activities such as swimming and unlimited housework or shopping. As shown in Table 2, with the exception of minimum one-year KSSO, improvement in and absolute latest follow-up patient reported function (KSSF and UCLA Activity Level Score), walking and stair pain, and satisfaction (KSSS) did not significantly differ among native varus patients surgically corrected to neutral, valgus, or varus. The overall Kruskall-Wallis test of 
latest median KSSO scores was significant $(p=0.025)$ but post hoc comparisons between pairs of medians were not significant. Latest KSSO was highest among patients corrected from varus to neutral (97) followed closely by those corrected from varus and left in residual varus (95) and varus to valgus (93). When asked "Does this knee feel 'normal' to you?" $60 \%$ of native varus patients corrected to neutral, $40 \%$ of those corrected to valgus, and $64 \%$ of those left in residual varus responded "always" $\left(\mathrm{X}^{2}=6.087, p=0.193\right)$.

Separately, a correlative analysis regarding outcomes based on the degree of correction was performed. As shown in Table 3, patient reported outcomes also did not vary based on the amount of correction of preoperatively varus knees in $3^{\circ}$ increments $\left(0^{\circ}\right.$ to $2^{\circ}, 3^{\circ}$ to $5^{\circ}$, etc. $)(p \geq$ $0.118)$.

\section{Discussion}

Neutral mechanical alignment of the tibia and femur have a long history as the gold standard in TKA. [32] Robust evidence ties implant survivorship and good patient outcomes to neutral mechanical alignment. [1-8] Consequently, neutral mechanical alignment of $180 \pm 3^{\circ}$ has been considered imperative for successful implant functionality and longevity. [33, 34]

In recent discourse, however, evidence regarding the prevalence of constitutional varus alignment [25] and more "faithful" anatomic alignment [27] have compelled consideration of targets beyond neutral mechanical alignment to optimize the success of TKA. [35] Recent studies have shown that implant survivorship is equivalent in neutral and varus aligned knees $[11-13,36]$ and that the use of computer navigation for precision mechanical alignment has had less impact on clinical and functional outcomes than expected. [14-16] It is important to note, however, that consistent with historical data, a recent meta-analysis of 10 studies concluded that 
neutral or valgus alignment following TKA - not varus alignment - is essential to implant survival. [37]

Patient satisfaction with TKA ranges from 70-89\% following TKA, [17-23, 38, 39] indicating that approximately one in every five patients are not happy with knee replacement. While the causes of dissatisfaction are not yet fully understood, a national, multicenter study of 661 patients found that only $66 \%$ of patients reported that their knee felt normal following TKA, an observation unaltered by neutral mechanical alignment or modern knee implant designs. [24] These observations raise the important question of whether postoperative tibiofemoral alignment relative to preoperative alignment underlies dissatisfaction with TKA. Two studies comparing clinical and functional outcomes in postoperatively neutrally-aligned and varus knees have reported worse outcomes in the latter group; $[1,40]$ two have reported superior outcomes in patients left in residual varus; [26, 41] and five have reported no differences in outcomes in postoperatively neutrally-aligned and varus knees. [27, 36, 42-44] Collectively therefore, evidence to date reflects two in favor and seven against the idea that residual varus alignment may improve clinical and functional outcomes and subsequent satisfaction with TKA.

Findings from the current study also are inconsistent with the notion that patients with a preoperative varus limb alignment will have superior patient reported outcomes compared to those fully corrected to neutral alignment after TKA. Sixty-seven percent of the TKAs we studied were preoperatively varus knees. Minimum one-year patient function as measured by the new Knee Society function score $(p=0.632)$ and UCLA Activity Level $(p=0.245)$ were equivalent in native varus knees regardless of the direction of correction (neutral, varus, or valgus), as were Knee Society satisfaction scores $(p=0.883)$, pain during level walking ( $p=$ 0.721), and pain while climbing stairs $(p=0.457)$ scores. Only the new Knee Society objective 
score varied based on the direction of correction of native varus knees $(p=0.025)$. Minimum one-year KSSO was highest among patients corrected from varus to neutral (97) followed closely by those corrected from varus to varus (95) and varus to valgus (93), but post hoc pairwise comparisons of medians were not significant. The amount of pre- to postoperative improvement in outcomes did not vary based on the direction of correction of varus knees $(p \geq$ 0.423). Patient reported outcomes also did not vary based on the amount of varus correction in $3^{\circ}$ increments $\left(0^{\circ}\right.$ to $2^{\circ}, 3^{\circ}$ to $5^{\circ}$, etc.) $(p \geq 0.119)$. Similar to observations by Nam et al., [24] $60 \%$ of native varus patients corrected to neutral, $64 \%$ of those corrected to varus, and $40 \%$ of those corrected to valgus responded that their knee feels normal $(p=0.193)$.

It is a limitation of our study that preoperative and postoperative coronal alignment was measured as tibiofemoral angles on short knee radiographs rather than as hip-knee-ankle angles on full-leg radiographs. [45] Park et al. observed 14\% and 33\% discordance, respectively, for classification of preoperative and postoperative alignment as neutral, varus, or valgus based on short and full-length images. The radiographic limitation of our study should be carefully considered when comparing our findings to existing and future studies. To help offset this limitation, we compared patient-reported outcomes based on the amount of correction, which is independent of overall limb alignment and can be determined solely on short radiographs, of native varus knees in $3^{\circ}$ increments $\left(0^{\circ}\right.$ to $2^{\circ}, 3^{\circ}$ to $5^{\circ}$, etc.) and observed no significant differences in groups $(p \geq 0.118)$.

Implant alignment in the coronal plane is one aspect by which the surgical quality of TKA is assessed. Traditionally, based largely on the concept of implant stability and survivorship, it is held that postoperative tibiofemoral alignment should be within $3^{\circ}$ of neutral mechanical alignment $\left(0^{\circ}\right)$. It also is known however, that sagittal and rotational alignment 
contribute to successful TKA, as do soft tissue and ligament balance, and that these factors interact with one another and with coronal alignment to influence clinical and functional outcomes. New literature suggests factors other than alignment may have as much or more influence on outcomes following TKA. Mugnai and colleagues [46] recently reported that mean flexion-not intraoperative computer navigation parameters or pre- and post-operative radiographic alignment--were related to Knee Injury and Osteoarthritis Outcome (KOOS) scores at mean follow-up of two years. Fujimoto and colleagues [47] recently documented that postoperative varus and neutral alignment in a sample of knees with preoperative varus deformity influenced knee kinematics under weight-bearing conditions through posterior tibial slope and lateral femoral condyle mobility.

Affirmation [48] and opposition [49] to neutral mechanical vs. anatomical alignment in the coronal plane as a gold standard for successful TKA juxtapose years of research-based, standard practice avoiding coronal malalignment to enhance outcomes with more recent findings suggesting that neutral alignment may not be a natural condition for some patients. It could be argued that this dichotomy reflects fundamental differences of opinion regarding the purpose of TKA - to restore joint function even if it doesn't feel normal to patients or to recreate a functional joint that feels normal. It is possible that this discussion will shed light on why approximately $70-89 \%$ of patients are dissatisfied following TKA, but observations such as ours indicating that clinical and functional outcomes do not vary based on the direction (neutral, varus, valgus) or degree of correction of varus knees; and that equivalent proportions (60 to $64 \%$ ) of patients in native varus alignment surgically corrected to neutral or to residual varus alignment reported that their knee feels normal do not support those who affirm or those who 

of multifactorial, transactional causes of dissatisfaction with TKA is recommended.

263

264 
1. Choong PF, Dowsey MM, Stoney JD. Does accurate anatomical alignment result in better

267

268 function and quality of life? Comparing conventional and computer-assisted total knee arthroplasty. The Journal of arthroplasty 24(4): 560, 2009

2. Longstaff LM, Sloan K, Stamp N, Scaddan M, Beaver R. Good alignment after total knee arthroplasty leads to faster rehabilitation and better function. The Journal of arthroplasty 24(4): 570,2009

3. Fang DM, Ritter MA, Davis KE. Coronal alignment in total knee arthroplasty: just how important is it? The Journal of arthroplasty 24(6 Suppl): 39, 2009

4. Ritter MA, Faris PM, Keating EM, Meding JB. Postoperative alignment of total knee replacement. Its effect on survival. Clin Orthop Relat Res (299): 153, 1994

5. Cherian JJ, Kapadia BH, Banerjee S, Jauregui JJ, Issa K, Mont MA. Mechanical, Anatomical, and Kinematic Axis in TKA: Concepts and Practical Applications. Current Reviews in Musculoskeletal Medicine 7(2): 89, 2014

6. Berend ME, Ritter MA, Meding JB, Faris PM, Keating EM, Redelman R, Faris GW, Davis KE. Tibial component failure mechanisms in total knee arthroplasty. Clin Orthop Relat Res (428): 26, 2004

7. D'Lima DD, Hermida JC, Chen PC, Colwell CW, Jr. Polyethylene wear and variations in knee kinematics. Clin Orthop Relat Res (392): 124, 2001

8. Jeffery RS, Morris RW, Denham RA. Coronal alignment after total knee replacement. The Journal of bone and joint surgery British volume 73(5): 709, 1991

9. D'Lima DD, Chen PC, Colwell CW, Jr. Polyethylene contact stresses, articular congruity, and knee alignment. Clin Orthop Relat Res (392): 232, 2001 
10. Moreland JR. Mechanisms of failure in total knee arthroplasty. Clin Orthop Relat Res (226): 49, 1988

11. Parratte S, Pagnano MW, Trousdale RT, Berry DJ. Effect of postoperative mechanical axis alignment on the fifteen-year survival of modern, cemented total knee replacements. The Journal of bone and joint surgery American volume 92(12): 2143, 2010

12. Matziolis G, Krocker D, Weiss U, Tohtz S, Perka C. A Prospective, Randomized Study of Computer-Assisted and Conventional Total Knee Arthroplasty. Three-Dimensional Evaluation of Implant Alignment and Rotation 89(2): 236, 2007

13. Bonner TJ, Eardley WG, Patterson P, Gregg PJ. The effect of post-operative mechanical axis alignment on the survival of primary total knee replacements after a follow-up of 15 years. The Journal of bone and joint surgery British volume 93(9): 1217, 2011

14. Harvie P, Sloan K, Beaver RJ. Computer navigation vs conventional total knee arthroplasty: five-year functional results of a prospective randomized trial. The Journal of arthroplasty 27(5): 667,2012

15. Spencer JM, Chauhan SK, Sloan K, Taylor A, Beaver RJ. Computer navigation versus conventional total knee replacement: no difference in functional results at two years. The Journal of bone and joint surgery British volume 89(4): 477, 2007

16. Kamat YD, Aurakzai KM, Adhikari AR, Matthews D, Kalairajah Y, Field RE. Does computer navigation in total knee arthroplasty improve patient outcome at midterm follow-up? International Orthopaedics 33(6): 1567, 2009

17. Bourne RB, Chesworth BM, Davis AM, Mahomed NN, Charron KDJ. Patient Satisfaction after Total Knee Arthroplasty: Who is Satisfied and Who is Not? Clinical Orthopaedics and Related Research 468(1): 57, 2010 
18. Choi Y-J, Ra HJ. Patient Satisfaction after Total Knee Arthroplasty. Knee Surgery \& Related Research 28(1): 1, 2016

19. Dunbar MJ, Haddad FS. Patient satisfaction after total knee replacement. new inroads 96$\mathrm{B}(10): 1285,2014$

20. Robertsson O, Dunbar M, Pehrsson T, Knutson K, Lidgren L. Patient satisfaction after knee arthroplasty: a report on 27,372 knees operated on between 1981 and 1995 in Sweden. Acta orthopaedica Scandinavica 71(3): 262, 2000

21. Scott CEH, Bugler KE, Clement ND, MacDonald D, Howie CR, Biant LC. Patient expectations of arthroplasty of the hip and knee. Journal of Bone \&amp; Joint Surgery, British Volume 94-B(7): 974, 2012

22. Lau RL, Gandhi R, Mahomed S, Mahomed N. Patient Satisfaction after Total Knee and Hip Arthroplasty. Clinics in Geriatric Medicine 28(3): 349,

23. Baker PN, van der Meulen JH, Lewsey J, Gregg PJ. The role of pain and function in determining patient satisfaction after total knee replacement. Data from the National Joint Registry for England and Wales. The Journal of bone and joint surgery British volume 89(7): 893,2007

24. Nam D, Nunley RM, Barrack RL. Patient dissatisfaction following total knee replacement: a growing concern? The bone \& joint journal 96-b(11 Supple A): 96, 2014

25. Bellemans J, Colyn W, Vandenneucker H, Victor J. The Chitranjan Ranawat award: is neutral mechanical alignment normal for all patients? The concept of constitutional varus. Clin Orthop Relat Res 470(1): 45, 2012

26. Dossett HG, Swartz GJ, Estrada NA, LeFevre GW, Kwasman BG. Kinematically versus mechanically aligned total knee arthroplasty. Orthopedics 35(2): e160, 2012 
27. Howell SM, Howell SJ, Kuznik KT, Cohen J, Hull ML. Does A Kinematically Aligned Total Knee Arthroplasty Restore Function Without Failure Regardless of Alignment Category? Clinical Orthopaedics and Related Research 471(3): 1000, 2013

28. Scuderi GR, Bourne RB, Noble PC, Benjamin JB, Lonner JH, Scott WN. The New Knee Society Knee Scoring System. Clinical Orthopaedics and Related Research 470(1): 3, 2012 29. Noble PC, Scuderi GR, Brekke AC, Sikorskii A, Benjamin JB, Lonner JH, Chadha P, Daylamani DA, Scott WN, Bourne RB. Development of a new Knee Society scoring system. Clin Orthop Relat Res 470(1): 20, 2012

30. Amstutz HC, Thomas BJ, Jinnah R, Kim W, Grogan T, Yale C. Treatment of primary osteoarthritis of the hip. A comparison of total joint and surface replacement arthroplasty. The Journal of bone and joint surgery American volume 66(2): 228, 1984

31. Zahiri CA, Schmalzried TP, Szuszczewicz ES, Amstutz HC. Assessing activity in joint replacement patients. The Journal of arthroplasty 13(8): 890, 1998

32. Insall JN, Binazzi R, Soudry M, Mestriner LA. Total knee arthroplasty. Clin Orthop Relat Res (192): 13, 1985

33. Abdel MP, Oussedik S, Parratte S, Lustig S, Haddad FS. Coronal alignment in total knee replacement: historical review, contemporary analysis, and future direction. The bone \& joint journal 96-b(7): 857, 2014

34. Vandekerckhove PJ, Lanting B, Bellemans J, Victor J, MacDonald S. The current role of coronal plane alignment in Total Knee Arthroplasty in a preoperative varus aligned population: an evidence based review. Acta orthopaedica Belgica 82(1): 129, 2016

35. Allen MM, Pagnano MW. Neutral mechanical alignment: Is it Necessary? The bone \& joint journal 98-b(1 Suppl A): 81, 2016 
357

358

359

360

361

362

363

364

365

366

367

368

369

370

371

372

373

374

375

376

377

378

36. Magnussen RA, Weppe F, Demey G, Servien E, Lustig S. Residual varus alignment does not compromise results of TKAs in patients with preoperative varus. Clin Orthop Relat Res 469(12): 3443,2011

37. Liu HX, Shang P, Ying XZ, Zhang Y. Shorter survival rate in varus-aligned knees after total knee arthroplasty. Knee surgery, sports traumatology, arthroscopy : official journal of the ESSKA 24(8): 2663, 2016

38. Bourne RB, Chesworth B, Davis A, Mahomed N, Charron K. Comparing patient outcomes after THA and TKA: is there a difference? Clin Orthop Relat Res 468(2): 542, 2010

39. de Beer J, Petruccelli D, Adili A, Piccirillo L, Wismer D, Winemaker M. Patient Perspective Survey of Total Hip vs Total Knee Arthroplasty Surgery. The Journal of arthroplasty 27(6): 865, 2012

40. Matsuda S, Kawahara S, Okazaki K, Tashiro Y, Iwamoto Y. Postoperative alignment and ROM affect patient satisfaction after TKA. Clin Orthop Relat Res 471(1): 127, 2013

41. Vanlommel L, Vanlommel J, Claes S, Bellemans J. Slight undercorrection following total knee arthroplasty results in superior clinical outcomes in varus knees. Knee surgery, sports traumatology, arthroscopy : official journal of the ESSKA 21(10): 2325, 2013

42. Matziolis G, Adam J, Perka C. Varus malalignment has no influence on clinical outcome in midterm follow-up after total knee replacement. Archives of orthopaedic and trauma surgery 130(12): 1487, 2010

43. Waterson HB, Clement ND, Eyres KS, Mandalia VI, Toms AD. The early outcome of kinematic $<$ em $>$ versus $</$ em $>$ mechanical alignment in total knee arthroplasty. a prospective randomised control trial 98-B(10): 1360, 2016 
44. Young SW, Walker ML, Bayan A, Briant-Evans T, Pavlou P, Farrington B. The Chitranjan S. Ranawat Award : No Difference in 2-year Functional Outcomes Using Kinematic versus Mechanical Alignment in TKA: A Randomized Controlled Clinical Trial. Clin Orthop Relat Res, 2016

45. Park A, Stambough JB, Nunley RM, Barrack RL, Nam D. The Inadequacy of Short Knee Radiographs in Evaluating Coronal Alignment After Total Knee Arthroplasty. The Journal of arthroplasty 31(4): 878, 2016

46. Mugnai R, Zambianchi F, Digennaro V, Marcovigi A, Tarallo L, Del Giovane C, Catani F. Clinical outcome is not affected by total knee arthroplasty alignment. Knee surgery, sports traumatology, arthroscopy : official journal of the ESSKA 24(10): 3339, 2016

47. Fujimoto E, Sasashige Y, Tomita T, Kashiwagi K, Inoue A, Sawa M, Ota Y. Different femorotibial contact on the weight-bearing: midflexion between normal and varus aligned knees after total knee arthroplasty. Knee Surgery, Sports Traumatology, Arthroscopy 23(6): 1720, 2015 48. Lombardi AV, Jr., Berend KR, Ng VY. Neutral mechanical alignment: a requirement for successful TKA: affirms. Orthopedics 34(9): e504, 2011

49. Bellemans J. Neutral mechanical alignment: a requirement for successful TKA: opposes. Orthopedics 34(9): e507, 2011 


\section{Figure Legend}

Figure 1: Radiographic measurement of tibiofemoral angle 
Table 1: Preoperative and Postoperative Alignment of Native Varus Knees By Direction of Surgical Correction

\begin{tabular}{|c|c|c|c|c|c|c|}
\hline & $\mathbf{N}$ & Mean $^{\circ}$ & $\mathbf{S D}^{\circ}$ & Median $^{\circ}$ & Minimum $^{\circ}$ & Maximum $^{\circ}$ \\
\hline \multicolumn{7}{|c|}{ Preoperative Alignment Angles } \\
\hline Varus to Neutral Correction & 116 & -3.3 & 3.7 & -2.5 & -22.0 & 2.0 \\
\hline Varus to Varus Correction & 45 & -4.6 & 4.6 & -4.0 & -15.0 & 2.0 \\
\hline Varus to Valgus Correction & 15 & -3.2 & 3.7 & -3.0 & -11.0 & 2.0 \\
\hline \multicolumn{7}{|c|}{ Postoperative Alignment Angles } \\
\hline Varus to Neutral Correction & 116 & 5.0 & 1.6 & 5.0 & 3.0 & 8.0 \\
\hline Varus to Varus Correction & 45 & 0.8 & 1.6 & 1.0 & -5.0 & 2.0 \\
\hline Varus to Valgus Correction & 15 & 9.9 & 1.3 & 10.0 & 9.0 & 14.0 \\
\hline \multicolumn{7}{|l|}{ Delta Alignment Angles } \\
\hline Varus to Neutral Correction & 116 & 8.4 & 3.8 & 8.0 & 1.0 & 28.0 \\
\hline Varus to Varus Correction & 45 & 5.4 & 4.2 & 5.0 & -1.0 & 16.0 \\
\hline Varus to Valgus Correction & 15 & 13.1 & 3.7 & 13.0 & 8.0 & 20.0 \\
\hline
\end{tabular}




\begin{tabular}{|c|c|c|c|c|c|}
\hline & $\begin{array}{l}\text { Varus to } \\
\text { Neutral }\end{array}$ & $\begin{array}{l}\text { Varus to } \\
\text { Valgus }\end{array}$ & $\begin{array}{c}\text { Varus to } \\
\text { Varus }\end{array}$ & Statistic & $p$ \\
\hline Median KSSO & 97 & 93 & 95 & $\mathrm{H}=7.38$ & 0.025 * \\
\hline Median Delta KSSO & 52 & 52 & 51 & $\mathrm{H}=0.80$ & 0.669 \\
\hline Median KSSS & 38 & 37 & 38 & $\mathrm{H}=0.25$ & 0.883 \\
\hline Mean (SD) Delta KSSS & $20.2(8.1)$ & $20.2(12.3)$ & $20.8(8.7)$ & $\mathrm{F}=0.05$ & 0.954 \\
\hline Median KSSF & 79.0 & 80.5 & 79.5 & $\mathrm{H}=0.92$ & 0.632 \\
\hline Mean Delta KSSF & $38.1(19.6)$ & $38.9(18.0)$ & $32.5(21.0)$ & $\mathrm{F}=0.87$ & 0.423 \\
\hline Median Latest Walking Pain & 0 & 0 & 0 & $H=0.65$ & 0.721 \\
\hline Median Delta Walking Pain & -5 & -5 & -5 & $\mathrm{H}=0.09$ & 0.632 \\
\hline Median Latest Stair Pain & 1 & 1 & 1 & $\mathrm{H}=1.57$ & 0.457 \\
\hline Median Delta Stair Pain & -7 & -4 & -7 & $\mathrm{H}=1.17$ & 0.557 \\
\hline Median Latest UCLA Activity Level Score & 5 & 6 & 5 & $\mathrm{H}=2.81$ & 0.245 \\
\hline Median Delta UCLA Activity Level Score & 1.0 & 1.5 & 1.0 & $\mathrm{H}=1.22$ & 0.542 \\
\hline
\end{tabular}




\begin{tabular}{|c|c|c|c|c|c|c|c|}
\hline & $0-2^{\circ}$ & $3-5^{\circ}$ & $6-8^{\circ}$ & $9-11^{\circ}$ & $\geq 12^{\circ}$ & Statistic & $p$ \\
\hline $\mathrm{N}$ & 17 & 28 & 60 & 37 & 34 & & \\
\hline Median KSSO & 97 & 96 & 95 & 97 & 95.5 & $\mathrm{H}=2.28$ & 0.681 \\
\hline Median Delta KSSO & 48.5 & 50 & 52.5 & 50 & 55.5 & $\mathrm{H}=7.36$ & 0.118 \\
\hline Median KSSS & 36 & 36 & 36 & 38 & 40 & $\mathrm{H}=3.06$ & 0.547 \\
\hline Mean (SD) Delta KSSS & $\begin{array}{l}21.7 \\
(5.7)\end{array}$ & $\begin{array}{l}18.1 \\
(6.2)\end{array}$ & $\begin{array}{r}21.9 \\
\quad(7.8)\end{array}$ & $\begin{array}{l}18.8 \\
(9.3)\end{array}$ & $\begin{array}{c}21.1 \\
(11.6)\end{array}$ & $F=0.96$ & 0.430 \\
\hline Median KSSF & 72 & $82 y$ & 78.5 & 80.5 & 78 & $\mathrm{H}=2.00$ & 0.736 \\
\hline Mean Delta KSSF & $\begin{array}{c}31.9 \\
(13.3)\end{array}$ & $\begin{array}{c}43.0 \\
(21.3) \\
\end{array}$ & $\begin{array}{c}37.8 \\
(14.5)\end{array}$ & $\begin{array}{c}33.4 \\
(20.4)\end{array}$ & $\begin{array}{c}35.4 \\
(27.1)\end{array}$ & $\mathrm{F}=0.84$ & 0.502 \\
\hline Median Latest Walking Pain & $0<$ & 0 & 0 & 0 & 0 & $\mathrm{H}=3.02$ & 0.555 \\
\hline Median Delta Walking Pain & -4 & -5 & -5.5 & -4 & -5 & $\mathrm{H}=1.99$ & 0.737 \\
\hline Median Latest Stair Pain & 1 & 1 & 1 & 0 & 0.5 & $\mathrm{H}=2.71$ & 0.607 \\
\hline Median Delta Stair Pain & -7 & -7 & -6 & -5 & -7 & $\mathrm{H}=3.42$ & 0.491 \\
\hline Median Latest UCLA Activity Level Score & 5 & 6 & 5 & 6 & 5 & $\mathrm{H}=1.48$ & 0.831 \\
\hline Median Delta UCLA Activity Level Score & 2 & 1 & 1 & 1.5 & 1 & $\mathrm{H}=3.44$ & 0.487 \\
\hline
\end{tabular}




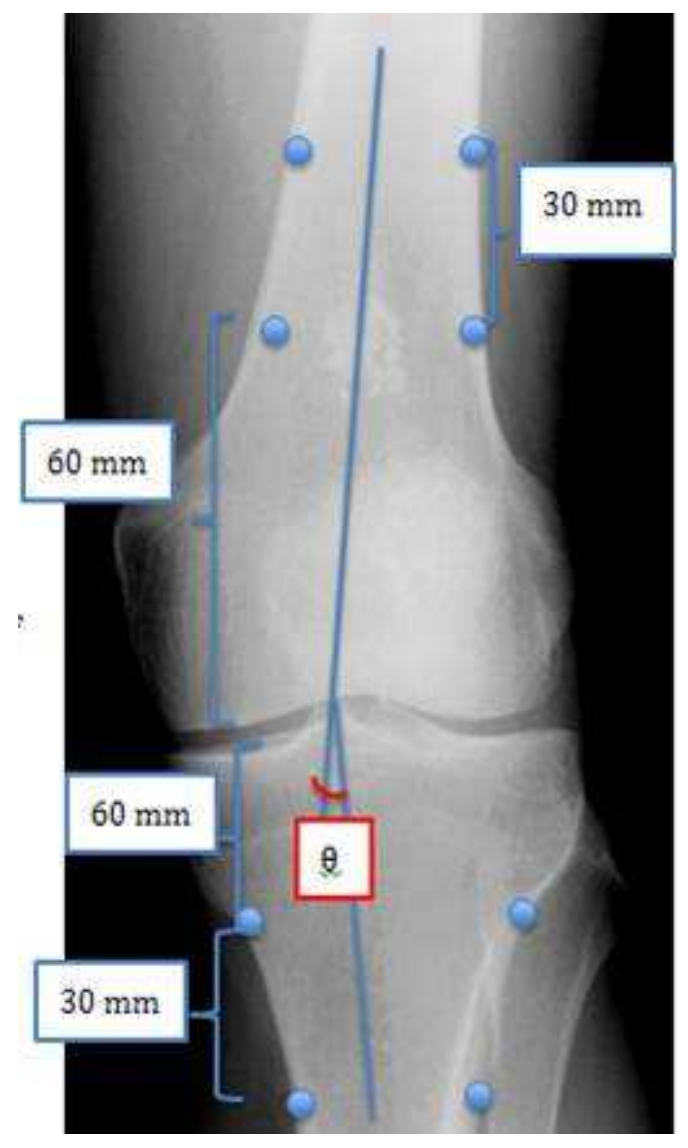

